\title{
Erratum: Vacuum ultraviolet circularly polarized coherent femtosecond pulses from laser seeded relativistic electrons [Phys. Rev. ST Accel. Beams 14, 030706 (2011)]
}

N. Čutić, F. Lindau, S. Thorin, S. Werin, J. Bahrdt, W. Eberhardt, K. Holldack, C. Erny, A. L'Huillier, and E. Mansten (Received 16 May 2011; published 27 May 2011)

It has been kindly notified to us by Giovanni De Ninno (Sincrotrone Trieste, Italy) that our statement in the abstract ("Currently, this setup is the only source worldwide producing coherent fs-light pulses with variable polarization in the vacuum ultraviolet.") is incorrect.

The Elettra storage ring free-electron laser has achieved coherent harmonic generation $(\mathrm{CHG})$ in circular polarization at $133 \mathrm{~nm}$ [1]. CHG at $87 \mathrm{~nm}$ has later also been obtained [2].

The main conclusion from our article is valid in the sense that this is, to date, the shortest published wavelength of helical coherent radiation, here achieved by CHG utilizing an APPLE II undulator in helical mode $(66 \mathrm{~nm}$, the 4th harmonic of a $263 \mathrm{~nm}$ seed laser).

[1] G. De Ninno, E. Allaria, M. Coreno, F. Curbis, M.B. Danailov, E. Karantzoulis, A. Locatelli, T. O. Mentes, M. A. Nino, C. Spezzani, and M. Trovo, Phys. Rev. Lett. 101, 053902 (2008).

[2] G. De Ninno (private communication).

Published by the American Physical Society under the terms of the Creative Commons Attribution 3.0 License. Further distribution of this work must maintain attribution to the author(s) and the published article's title, journal citation, and DOI. 